\title{
The importance of criminal profiling in judicial investigations
}

\author{
Romina Popescu, Călin Scripcaru
}

\begin{abstract}
Romina Popescu - Lawyer graduated, „Stefan cel Mare” University Suceava, Romania
Călin Scripcaru - MD, PhD, professor, „Stefan cel Mare” University Suceava, Institute of Forensic Medicine Iaşi, Romania
\end{abstract}

\begin{abstract}
The psychological analysis of the criminal behaviour has a great importance in terms of prevention and investigation of crimes that were committed by the same perpetrator. The psychological profiling method is very popular in the USA, but also in Western Europe, unlike Romania, being an imperative scientific method that is used in criminal investigations, helping investigators to identify unknown criminals.
\end{abstract}

This subject is treated very rare in Romania, mainly due to the lack of specialists who would need a lot of experience and an extensive knowledge base from different fields of study such as: criminology, psychology, forensic medicine, psychiatry, sociology, law, etc.

\section{KEY WORDS:}

Profiling, crime, investigation.

\section{INTODUCTION}

Forensic profiling is an investigative strategy used by law enforcement to identify suspects and has been used to link cases that had the same author.

Several offenses can be linked to a specific offender and the profile achieved can be used to predict the future actions of the identified offender. In the ' $80 \mathrm{~s}$, most researchers believed that criminal profiling was relevant only in the case of sexual crimes, such as serial rape or sexual homicide, but since the late ' 90 s, research has been conducted to

support the applicability of profiling in the cases of arsonists and later in the cases of terrorists or thieves.

Psychological profiling is described as a method of identifying suspects, aiming to identify the mental, emotional and personality characteristics of a person based on the things that were done or left at the crime scene. According to Gregg O. McCrary, "the basic premise supports the idea that behavior reflects personality."(1) 
There are two major assumptions made when it comes to profiling criminals: behavioral consistency and homology. Coherence of behavior is the idea that the crimes of an author will tend to be similar to each other. Homology is based on the idea that various similar crimes are committed by similar criminals.

The fundamental assumptions on which the profiling of an author is based, such as the homology hypothesis, have been proven to be overtaken by advances in the field of psychology and behavioral science (2).

Mainly, the profiling approaches assume that the whole behavioral ensemble is determined by personality, and not by situational factors.

\section{MATERIAL AND METHOD}

\section{Basic principles of the criminal profiling method}

First of all, the principles that support the method of psychological profiling are based on the "on spot" research. Any other forms of activity, such as determine the behavioral typology, the deviant past and the predictions that refer to the author consist in types of activities that derive from taking the first steps in terms of investigation at the crime scene.Usually, the crimes that are suitable of using the psychological profiling techniques are: serial crimes, serial rapes, particularly serious murder, infanticide, robberies that are followed by the death of the victim or crimes committed against minors.(3)

\section{The information needed to compile the psychological profile}

Like any other activity that has a well-defined foundation constructed from a scientific point of view, the process of elaborating the psychological profile must go through several imperative stages:

\section{Crime Data - Data entry and processing}

During this stage, all available data on offenses that are suspected to be related will be processed, including data on locations and directions, summarizing them in spatial information. At the same time, information about the modus operandi, the date of committing the deed, the typology of the crime, etc. will be processed.

\section{Geographic Data - Geographic data analysis}

It refers to the analysis of data that may contain leads in regards with geographical references of the location where, for example, the victim was last seen. Therefore, this analysis requires a series of data that has a major importance for the study and for the final result, and we are going to mention here: the exact location, demographic characteristics of the area, photos and maps, as well as the general description of the perimeter to include data on crime rate, census, standard of living, etc.

\section{Victimology - Victim analysis}

In regards with the cases of each victim, data will be processed on age, sex, race, occupation, residence and others. These relatively general leads will be accompanied by data on social activities, routes and means of transportation used, hobbies, etc., thus calculating a potential victim. In short, we will want to know as many details as possible about the victim because even the smallest detail can be decisive in correlating an author with the victim, and thus with the deed.

\section{Behavioral analysis / Psychological profile}

The psychological profiling process of a crime author has a substantial role in terms of developing the geographical profile. Thus, the investigators will be able to determine a psychological status but also a potential lifestyle of the perpetrator. 


\section{Suspect Data - Suspect analysis}

As in the case of the victim, data will be collected and processed regarding age, sex, race, criminal record, current and past residence, psycho-pathological history, graduate schools, current and former jobs, social activities and hobbies of the suspect. In the same time, there is data that will be processed from the members of his family and his friends, taking into account various options such as those in which he was helped or in which he told someone close to him about what he was going to do.

\section{THE ELABORATION TECHNIQUE OF} A PSYCHOLOGICAL PROFILE

\section{Main objectives}

The profiling technique that was developed by the FBI has three main objectives:

- the evaluation - from a psychological and social point of view - of an unknown author. Starting from this objective, the involvement of a series of hypotheses regarding age, race, sex, religion, domicile, job, etc. is found. The profilers support their assumptions based on the dynamics of the samples and photographs that were taken at the crime scene, on the forensic reports and on their knowledge of overall victimology. In addition, they will use statistical truths, deductive and inductive reasoning, professional and personal experience.(4)

- the evaluation - from a psychological point of view of a stolen property from the crime scene/victim by the author - this objective is based on the analysis of trophies or souvenirs stolen by the perpetrator in order to feed the fantasies he has. Therefore, we want to analyze the psycho-behavioral signature of the author, i.e. the behavior from which his personality is reflected. At the same time, it is wanted to analyze the criminal motivation, ie what he did and what he did not do on the spot. A well-defined psychological profile must be a scientific experiment that aims to provide investigators with all the parameters necessary to identify the author.

- issuing special interrogation techniques and issuing investigative strategies (proactive psychological profile). The investigative strategies will be developed throughout the entire process, in order to direct the investigators that are involved, to the area of correct hypotheses, thus saving time, resources and saving other potential victims by bringing the perpetrator to answer in front of the jury.

\section{MODUS OPERANDI vS. PSYCHO- BEHAVIORAL SIGNATURE \\ Personality reflected in behavior}

Taking into account the psychological evidence, everything can be simplified and reduced to behavioral parameters, patterns and modes of externalization, which is why a profile investigator will have the duty to decipher and reconstruct such manifestations by interpreting the data he has available. A behavioral pattern may present major similarities in everyday expression in the case of suspects, but there are also exceptional cases in which such a pattern can be considerably altered.

\section{Modus operandi}

In a broad sense, modus operandi is the set of actions that were carried out by the perpetrator in order to ensure success in committing the act and in achieving the expected end.

The mode of operation was defined as "what an author must do to commit the crime". However, the mode of operation of any author contains the following basic elements(5):

- guaranteeing the success and completion of the crime; 
- protection of one's identity - an element from which the final objective of the deed also emerges: avoiding capture.(6)

\section{The ritual}

During the performance of criminal acts, the ritual is the behavioral pattern that exceeds the means and methods necessary to commit the crime. In other words, the ritual of a murderer can be considered as a genome of his signature, considered to be a ritual signature.

Such a ritual behavior can have its origin in the psycho-sexual needs, those being vital when it comes to the emotional satisfaction of the author. They are often rooted in fantasies that often involve paraphilia.

\section{Psycho-behavioral signature}

The psycho-behavioral signature contains a series of behavioral concepts. It was reported that: "something the perpetrator must do to be emotionally fulfilled; the signature is not necessary for the successful execution of the crime, but it is the reason why the perpetrator chooses that particular deed in that place...".

Therefore, from a methodical perspective, an individual's behavioral signature can be more easily investigated and understood if it relates to the modus operandi.

Modus operandi - The success of the crime is based on various principles such as: the choice of location and the victim, the method of attack, the use of brute force or a weapon, the premeditation of the deed, etc. Furthermore, the stolen goods and the incriminating materials found on the spot (evidence) will be taken into account.

\section{Results}

In 1986, the naked body of a young woman was discovered at 3 P.M. on the terrace of the apartment building where she was living. She had been brutally beaten and then strangled with the strap of her purse. (9)

Various messages were found on the victim's body, written on the skin by the author, such as "you can't stop me" - on the thighs and "damn you" - on the abdomen.

A pendant in the form of the Jewish sign "Star of David" that she always wore around her neck was missing and was supposed to have been taken by the murderer. The victim's underwear had been pulled over her face. The stockings she wore were used by the author to tie her to her wrists to the railing.

The victim's nose and jaw had been broken and her molars had been removed from her mouth. Traces of bites and scratches were also found on her body, all of which were made post-mortem. In addition, the victim had multiple skull fractures, allegedly caused by a blunt object. At the scene, investigators established that the victim was strangled to death.

At the end of the criminal act, the perpetrator defecated near the body and covered his organic matter with the victim's clothes.

\section{Factors that contribute to the establishment of the profile}

Regarding the evidence at the crime scene, everything that was used by the perpetrator to commit the crime belonged to the victim. Following a first expertise, it is found that the offender did not plan his deed, not having a weapon, rope or tape for the victim's mouth.

He probably didn't even planned to meet his victim that morning. The crime scene indicated a spontaneous event. The crime 


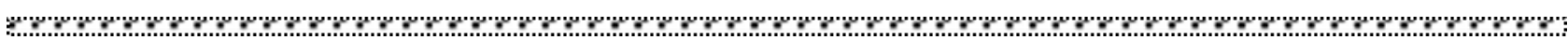

scene is different from the death scene. The initial abduction took place at the stairwell, then the victim was taken to a more isolated area.

It is assumed that the victim woke up around 6:30, got dressed, drank her coffee and left her apartment in order to go to work in a care centre for the needy, where she was employed as a teacher for disabled children.

The victim lived with her parents. When she left for work in that morning, she would've took the elevator or walk down the stairs, depending on her mood. According to relatives, the victim had been a quiet young woman.

At the same time, during the forensic investigation it was established that the victim was sexually assaulted, being found traces of semen on her body.

Due to the fact that the perpetrator did not use any specific weapon, investigators determined that he was not prepared to commit that crime. It was indicated that, most likely, the perpetrator used his fists to leave the victim unconscious, which is why the residents did not hear any screams.

No deep wounds were found and the knife that was used to mutilate the victim's breast was not a large one, but probably a small knife that the offender could legally wear.

The preliminary police report showed that another resident of the apartment building, a 15 -year-old man, discovered the victim's wallet on the stairs, located between the third and the fourth floor at about 8:20 A.M. He kept his wallet until he returned home from school that afternoon. At that moment, he handed the wallet to his 40-year-old father. His father went to the victim's apartment at
2:50 P.M. and handed the wallet to the victim's mother.

When the victim's mother called the care centre to inform her daughter about the wallet, she learned that she has not been at work in that morning. The victim's mother, sister and a neighbour started looking for her in the building, as they were those who had discovered the body.

\section{The decision-making process}

The style of this crime was unique, which led the investigators to place the perpetrator in the realm of sexually motivated criminals.

There is a degree of planning indicated by the organization and sophistication of the crime scene. The idea of murder had probably preoccupied the author's mind for some time. Maybe sexual fantasies started by collecting sadistic pornographic material.

The victim lived a lonely life and was not the kind of person who could fight an attacker.

Based on the information gathered by investigators about the occupation and lifestyle of the victim, it was agreed that the victim could've easily been placed into the category of low-risk victims, living in an area with a relatively low crime rate.

The author committed the crime during the day and there was a possibility that other people would've see him. Apparently, it happened that the victim got in the way of the perpetrator at the right time.

No escalation factors were present. The time the criminal spent with his victim significantly increased his risk of being caught in the middle of the crime. Therefore, it was found that the author was familiar with that area. 


\section{Crime assessment}

The crime scene indicated that the murder was an isolated event that is not part of a series of events. Also, all the indications convinced the investigators that the author had acted in this way for the first time, without being too organized.

The subject had to kill the victim in order to fulfil his sexual fantasies. The killer was in a familiar territory and therefore had a reason to be there at 6:30 a.m.: he either lived or worked there.

The control of the criminal over the victim was carried out by brute force, punching the victim and thus providing a first indication of his intention. The victim is likely to be selected because she posed a minor, or even null, threat to the offender.

Because she did not fight, run or scream, it seems that she did not perceive her kidnapper as a threat. Either she knew him (because she had seen him before), or she didn't seem threatening (maybe he was dressed like an ordinary man, like a postman, or a businessman), and therefore his presence in the building did not alarmed the victim.

The perpetrator left his victim unconscious after the first blow, lifted her and took her to the terrace of the building and implemented his fantasies, undressing her, tying her up and taking advantage of her.

It was very likely that the author knew that no one would come to the roof to disturb him, which clearly shows his familiarity with the area - it was assumed that the author visited that terrace several times at different times.

Sadistic ritualistic fantasy generated sexual motivation for murder. The killer displayed total domination in front of the victim. In addition, he placed the victim in a degrading position, reflecting his lack of remorse over the killing.

The murder was opportunistic. The crime scene depicted the complications of a deadly fantasy for a long time. Once the killer had a victim in mind, he had also made a plan for killing and abusing the body. However, in the context of the crime, the profiling technique notes a paradox: covered faces. Defecation was not part of the ritual fantasy and was thus covered. The presence of faces also supports the length of time required for the crime, the control that the killer had over the victim (her unconscious state) and the knowledge that he will not be interrupted.

The victim's position in that certain way indicates that the offender had seen such images before, probably in his collection of sadistic pornographic materials.

He positioned her earrings in a ritualistic manner and scribbled various words on her body. This, again, reflects an image that he had probably repeated in his mind. In addition, he took her necklace as a souvenir. Related to this fact, it is worth mentioning that the author positioned the victim's body in a shape very similar to the Star of David (the Jewish symbol that the woman wore around her neck).

\section{Criminal profile}

Based on the information that was obtained during the previous stages, the profile of the criminal was generated.

A physical description of the suspect pointed out that the perpetrator was a man, between 25 and 35 years old, close to the victim, and with a mediocre appearance. $\mathrm{He}$ was supposed to have an average level of intelligence and to be a dropout. He would 
к $\%$ о

have no military history and could be unemployed. His potential job would have been that of a home craftsman. It was also alleged that alcohol or drugs were not among his vices, as the murder took place in the morning.

The suspect allegedly had difficulty maintaining any personal relationships with other women. There was a possibility that he was following women younger than him, because he needed to be able to dominate and control relationships. It was also assumed that the subject had sadistic tendencies, which was found in the atrocities committed on the victim's body.

In addressing the killer's habits, the profile revealed that he had a reason to be in the building at 6:30 in the morning. There is a possibility that the individual was employed in the apartment complex or resided in the complex.

Although the offender might have preferred his victim to be conscious, he had to bring her to that state in order to avoid the risk of being caught. He didn't want the woman to cry for help.

Sexual and sadistic acts on an inanimate body suggest that it was disorganized. He probably was a very confused person with mental dysfunction. The fact that he performed such acts on a dead or unconscious person indicated that he is incapable of having a normal relationship with someone.

The crime scene reflected that the perpetrator did not feel any remorse. He left the victim in a provocative, humiliating position, just as he wanted her to be found. He ridiculed the police with the written message on the victim; the messages also indicated that the subject could kill again.

\section{The investigation}

The crime was highly publicized in the local press, being an extraordinary event, especially in that low crime area.

They immediately gathered in a group of about 26 investigators. It all resulted in an intensive investigation that included a series of interviews and discussions with over 2,000 people. Known sex offenders in the area failed to provide any assistance to investigators.

\section{The result of the investigation}

A suspect was detained 13 months after the discovery of the victim's body. After receiving the criminal profile, the police examined the cases of 22 suspects who were interviewed. A man stood out. The suspect's father lived in the same apartment building as the victim. Initially, the police interviewed his father, who stated that he had a son staying at the local psychiatric hospital. Police later found out that his son had left before treatment hours without the permission of a doctor right before the day of the crime.

They also learned that he was an unemployed man living alone. His mother died when he was 19 years old (11 years before). He dropped out of school. He was a 30-year-old man, single, living with his father.

Following the searches that took place in his house, a collection of sadistic pornographic materials was discovered. He had never been in the army, had no relationships and was described as being insecure with women. The man was suffering from certain psychiatric disorders (depression) and was receiving treatment. He had a history of repeated suicide attempts (hanging / asphyxiation) both before and after the crime. 
r.m\%\%\%

The police discovered that the security of the psychiatric hospital was lacking, as he had the opportunity to enter and leave the hospital at will.

However, among the most conclusive evidence against him was the semen collected from the victim's body (DNA sample) and fingerprints. Three renowned dentists performed independent tests and all agreed that the marks of the suspect's teeth matched with the ones of the bites that were found on the victim's body.

\section{CONCLUSIONS}

Criminal profiling has been proven as an extremely useful tool for law enforcement and for solving violent crimes, which seem to have no reasons. The process has significantly helped to resolve many cases over the past decade. It is believed that through the research efforts of FBI staff, the National Centre for Violent Crime Analysis and of professionals from other countries, the profiling process will continue to be refined and will be a viable law enforcement investigation aid.

The profiling investigator will aim to predict the probable characteristics of an unknown offender, analysing the behavioral patterns and other clues.

Criminal profiling arose from the first attempts in which criminologists tried to explain a crime and tried to predict the criminal potential of an individual. It then moved on to the next stage, being used to develop the psychological profiles of presidents (for informational purposes only, not to investigate crimes). Subsequently, psychiatrists and psychologists began to outline psychological profiles, as they believed that it could help the police to find unknown killers. Following this stage, the FBI found that psychological profiles were indeed very useful in their investigations, managing to bring to justice many serial killers from the first practical applications of this technique.

Today, criminal profiling has become one of the most controversial and useful crime investigation techniques. Professionals such as those from the American Psychological Association, the Academy of Legal Sciences, and the Society for Psychology and Criminal Police are the ones best suited to assist other states with access to the database that they would need in order to adopt the technique of forensic profiling.

It can be seen that criminal profiling is a multidisciplinary practice that requires knowledge and experience in areas such as criminology, psychiatry, psychology, sociology and law. Psychiatrists, psychologists, criminologists and other law enforcement officers play a very important role, not only in criminal investigations, but also in the development of measures and programs that are meant to prevent crimes, this being the next direction in which profiling tends to be used ("Potential" criminals). Therefore, the future of criminal profiling looks very interesting and will prove to be an invaluable technique for investigating and preventing crime.

In this age where the crime rate reaches very high levels, when everything becomes much easier for any potential offender, referring here to the ease with which they can disguise a criminal act, it is necessary to adapt the methodology used by investigators. In addition to the local techniques used in the field of forensics, the option of adopting Western methods that have been proven to be viable over time must also be considered. 
Bulletin of Integrative Psychiatry $\bigcirc$ New Series ODecember 2020 ○ Year XXVI ONo. 4 (87)/75 r Although in Romania this technique is barely used, it has been implemented sometimes, without taking into account too much the strictness of the criteria used to elaborate a criminal profile because, unfortunately, there are no such specially trained people that could go out on the field and apply such techniques.

\section{ACKNOWLEDGEMENTS AND DISCLOSURES}

The authors declare that they have no potential conflict of interest to disclose.

\section{REFERENCES}

1. Douglas J. E., Olshaker M. 1996. Mindhunter: Inside the FBI's Elite Serial Crime Unit, Ed. Pocket Books, New York, p. 26.

2. Thio, A. 1988. Deviant behaviour. Ed. Harper Collins Publishers, New York, pp. 157-160

3. Lăpăduși V., Grejdinoiu S. Considerații privind investigarea criminalistică a locului faptei”, Simpozionul Investigarea criminalistică a locului faptei, București. 2004, pp. 6-11.

4. O’Connell J., Soderman H. 1936. Modern Criminal Investigation, Ed. Funk Wagnalls, New York, pp. 254-260

5. Douglas J., Olshaker M. 1998. Obsession, Ed. Scribners, New York, p. 42

6. Keppel, R. 2005.Serial Offenders: Linking Cases by Modus Operandi and Signature, Ediția a doua, Ed. CRC Press, Boca Raton, pp. 620-621

7. Burges A., Hartman C., Resler R., Douglas J., McCormack A. Sexual Homicide. Journal of Interpersonal Violence, Nr. 3/ 1986, pp. $251-272$

8. Douglas J., Olshaker M. 1998. Obsession, Ed. Scribners, New York, p. 38

9. Douglas J. et. al., FBI Records: The Vault. Criminal Profiling from Crime Scene Analysis. https://vault.fbi.gov/Criminal\%20Profiling/Criminal\%20Profiling\%20Part\%202\%20of\%207/view

\section{Correspondence:}

Romina Popescu,

Lawyer graduated, „Stefan cel Mare” University Suceava, Romania, popescu.romina@ outlook.com

Submission: 29 oct 2020

Acceptance: 30 nov 2020 